\title{
Creating a Networking Lab for Business Students
}

\author{
Michael A. Chilton \\ Kansas State University, Manhattan, KS, USA
}

\author{
mchilton@ksu.edu
}

\begin{abstract}
When faced with a decision to acquire and install a networking lab for business students, the question looms as to the purpose and the learning objectives for such a lab. In addition, the technology is expensive and the effort required to set up the lab, define its pedagogical focus and prepare experiments that help achieve this focus can be a daunting task. However, modern business colleges must incorporate state of the art networking technologies into its curriculum and provide an opportunity for students to learn by doing. This paper presents the results of the creation of a networking lab including its physical setup, discusses the obstacles faced during its implementation and how they were overcome, and provides a roadmap for educators interested in adding a similar lab to their school. (Funding for the lab was generously provided by a group of alumni with a match from their employer for the specific purpose of creating a networking laboratory.) The lab is intended for business students majoring in Information Systems who must be prepared to make decisions concerning the acquisition and implementation of networking.
\end{abstract}

Keywords: Networking lab, servers, networking software, switches, implementation

\section{Introduction}

Responding to a recent query regarding the value of teaching networking in the college of business, I posed this simple (Socratic) answer: If you were a manager at a major corporation and needed to upgrade your networking capacity, would you be able to make an intelligent choice as to what router to purchase? When asked for more networking resources, can you understand and (more importantly) evaluate what your technical experts are telling you? Or are you simply taking what these experts tell you at face value and writing a check? More importantly, do you have the ability to distinguish between two or more technical solutions and compare their ability to meet the needs of the business? There are many scenarios we might imagine as extensions of this situation, but when the stockholders want to see maximum profits and reduced costs and the board of directors discovers a cash sink in the information technology department, it is the manager who must evaluate the choices being presented to him by his technical staff and make those decisions that have the greatest value to the organization, yet can be obtained and implemented at the least cost. These decisions involve making choices from among the technological alternatives presented to the manager, and they are decisions that any manager might be faced with because today's businesses operate using IT-reliant systems (Alter, 2003). The IS discipline includes net-

Material published as part of this journal, either on-line or in print, is copyrighted by Informing Science. Permission to make digital or paper copy of part or all of these works for personal or classroom use is granted without fee provided that the copies are not made or distributed for profit or commercial advantage AND that copies 1) bear this notice in full and 2) give the full citation on the first page. It is permissible to abstract these works so long as credit is given. To copy in all other cases or to republish or to post on a server or to redistribute to lists requires specific permission from the publisher at Publisher@InformingScience.org working because it is only through a connected system that users can interface with the back end applications and databases. But are we training our business students correctly in this critical area? While the answers to this question are still out and will be for some time, this paper introduces a networking lab whose pedagogy fo- 
cuses on this important issue. Activities conducted by students in the lab helps them learn how to mesh the underlying needs of the business with the technical issues that affect resource acquisition, replacement, maintenance and administration as the networking infrastructure grows.

There are several obstacles to overcome in order to create an effective networking lab. The first is cost. Because the technology is not cheap, acquiring the necessary hardware and software and maintaining it may prove to be prohibitive for some institutions. Another obstacle is the effort required to prepare the lab and select the appropriate experiments. The experiments will affect the software and hardware needed in the lab and they must be selected so that they cover the subject adequately. They must also be pre-tested so that the time required to perform them is manageable and that any unanticipated problems the students might have as they work through them can be identified and dealt with prior to the students beginning work. Lab manuals that cover the important topics for business students are few and far between, and so additional effort may be required in creating these experiments from scratch. The currency of the technology is yet another obstacle that affects decisions regarding the lab. That is, is the hardware and software that we utilize the most current? How current does it need to be? Does it have the right mix of functionality to be able to demonstrate the concepts covered in the classroom? Although these issues can be significant impediments, they need not be prohibitive, and in fact can be overcome with some effort. If overcome, the result can be an effective networking lab that enhances both technical and managerial topics.

The purpose of this paper is to address these issues and describe a lab setting for networking for business students. The paper opens with a description of the lab setup as actually implemented. Business students must learn how to make decisions of IT acquisition, implementation and maintenance and so classroom presentation of the technical theory and concepts as they relate to business needs is discussed next. The issues of currency and cost are addressed within this discussion, because implementing a lab must be done with the idea in mind that it will soon become obsolete and will need to be updated and/or upgraded, and that either the initial acquisition and/or later updating and maintenance can be expensive. An effective lab can be obtained and implemented very inexpensively. The lab experiments are discussed and shown how they support the dual objective of learning the technology and relating the technology to the needs of a business. Finally, the results of the lab are discussed using some quantitative and qualitative measures and the implications for educators are summarized.

\section{Lab Description}

The equipment in the lab consists of 10 computers (eight workstations and two rack mounted servers); three switches (two unmanaged 8-port boxes and one Cisco 2900 series XL 24-port switch); two VPN capable routers, each with a 4-port internal switch and one Cisco PIX-501 firewall, which also provides VPN capability; all necessary cabling and network interface cards; one uninterruptible power supply (UPS); one digital audio tape backup unit; and one laser printer. The network topology is shown in figure 1. A KVM (keyboard, video, mouse) switch was used on the rack to switch a single monitor, mouse and keyboard back and forth from one server to another. The workstations were outfitted with removable hard drives so that each lab group could maintain their experiments on a disk without affecting other groups or having to reset the computers when they were finished.

The workstations were arranged in a rectangular room with four computers on each side. The two 8-port switches received the cabling from each workstation and each switch was up linked into one of the two routers. The WAN port on each router was connected to the 24-port Cisco switch. Each server was also connected to the Cisco switch. The servers were mounted on a rack (with wheels) and placed into an adjacent closet along with the UPS, the Cisco switch and the tape backup unit. Although the wiring could be adjusted at any time to meet changing needs, it was 
easier to leave the physical connections as they were and use the Cisco switch to electronically segment the LAN. (This switch is capable of creating virtual LANs using its management interface.) This capability also allowed us to keep the lab separate from outside networks, yet use one computer to access the Internet. The initial network diagram is shown in Figure 1. The network was modified throughout the semester slightly depending on the nature of the lab requirements.

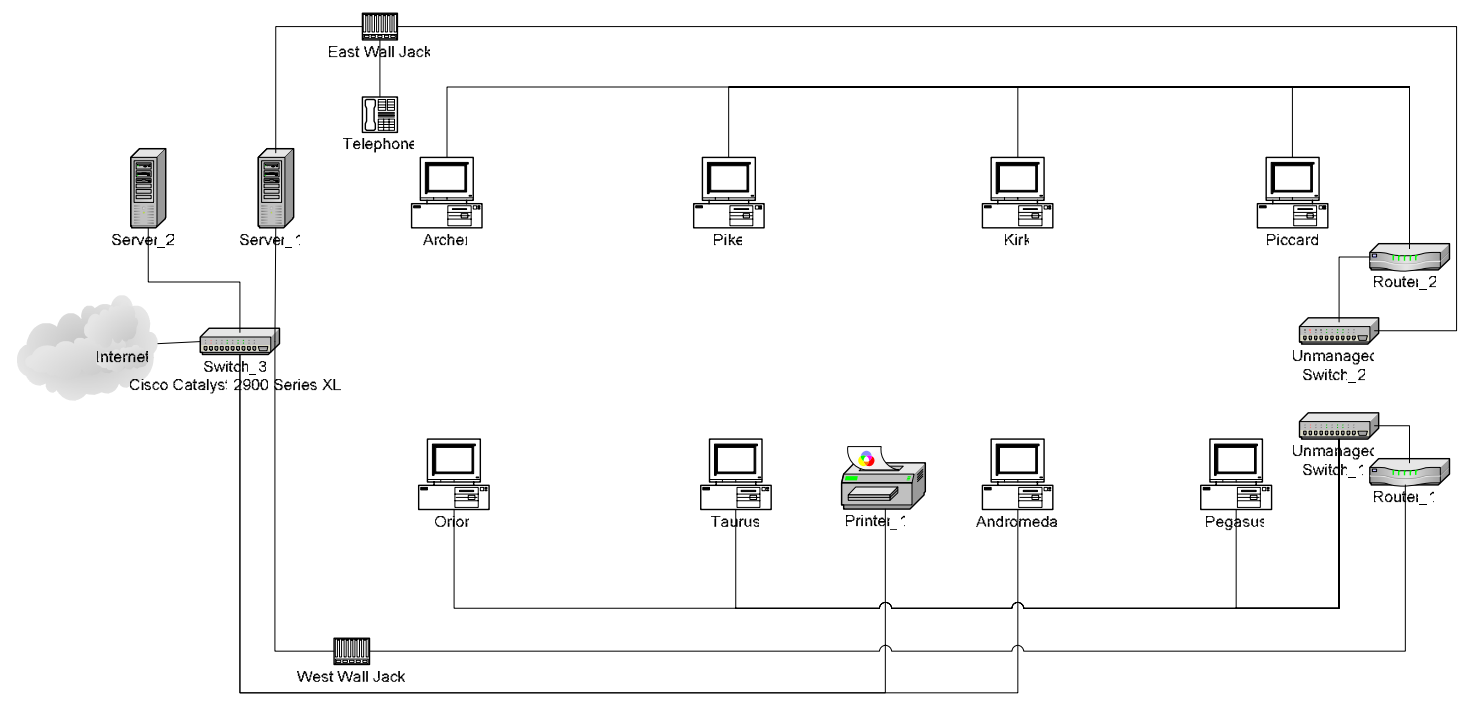

Figure 1: The Initial Networking Lab Layout

Each workstation was loaded with either Windows 2000 Professional or Windows XP professional, and the servers were loaded with Windows 2000 Advanced Server and Linux. Application software was either purchased for use in the lab or acquired as freeware from various Internet sites. Included in this application mix were the Apache web server (available free at www.apache.org), ethereal (a packet "sniffer" available at no charge from www.ethereal.org, Lotus Domino and Lotus Notes e-mail servers and client (available free from IBM through the IBM Scholars Program at http://www-3.ibm.com/software/info/university/) and other packages for which the university already had a site license. These packages included antivirus software, tape backup software, the operating systems and imaging software.

Our servers are considered to be entry level technology, but they incorporate some sophisticated features including dual network interface cards attached to the motherboard and an application specific integrated circuit (ASIC) that monitors such things as CPU temperature and cover tampering and reports these conditions to a remote station. Each server has 1 gigabyte of RAM and a RAID controller that allows the data to be striped across four 36 gigabyte (SCSI) hard disks.

The total approximate cost for the lab was under $\$ 15,000$. The bulk of this expense was the servers, and though we purchased two, we could have easily met our objectives with only one, which would have cut the cost nearly in half. It should be noted that a room was available for the placement of the lab, the size of which (12' x 18') is roughly equivalent to a small classroom, and this was not figured into the cost. Additionally, the workstations were acquired from our general use lab when that lab was upgraded, and the cost of these machines was also not included. One way to reduce the cost of the lab is to forgo the purchase of separate servers and use one or two of the workstations as the server(s). So long as the workstations meet the minimum required hardware configuration, both the Linux and Windows 2000 Server operating systems will operate correctly. 
Another way to reduce costs for a networking lab is to utilize simulation. There are several simulation packages available that can be loaded on a general use lab computer or on a student's own computer. However, these packages focus mostly on network certification training or on performance monitoring of large networks. Although less costly than an actual networking lab, the teaching objectives and the content of the simulation packages may not mesh precisely with the needs of business students. Also, simulation labs may not accomplish the desired exposure to the technology (Hamza, Alhalabi, Hsu, Larrondo-Petrie, \& Marcovitz, 2003).

Information technology, particularly networking technology, changes rapidly. If this is the case, then much of what we teach can become obsolete a short time after the semester ends. How can we deal with such an ominous predicament? The answer to this question is simply that the concepts we teach must be those that are broad and general in nature, enduring over time and either conform to an accepted standard or are so popular as to be considered the de facto standard. In addition, much of the latest technology (particularly software) offers more features than are useful in the classroom. To be effective pedagogically, it must be simple and widely accepted. We don't need to introduce post-doctoral level technology into an undergraduate classroom, because this can only serve to confuse students rather than educate them.

Our Cisco switch, acquired by the University in 1998, entered the end of life program earlier this year and will no longer be offered for sale by Cisco after April, 2004. The cost of a replacement switch may be prohibitive for some, and so the importance of the question of currency of the technology as it impacts the training of our business students becomes immediately obvious. The answer to this question is found in what the switch has to offer in terms of augmenting the concepts learned in the classroom. The switch that we used is capable of separating its 24 ports into 64 different virtual LANs (each port can be configured to support multiple LANs); it uses either a serial, text-based interface or a web browser interface that features a sophisticated Java applet; it allows all traffic to be directed to a "network" port for monitoring; and it has many other features that would take more time to discover than a one semester course has room for. Given this functionality, it becomes clear that the switch can be used in the lab for quite some time.

The two VPN capable routers that we acquired retail for less than $\$ 100$ each. Each includes a firewall that provides effective isolation from upstream traffic and a four port unmanaged switch that provides effective bandwidth control for downstream traffic. The VPN capability allowed the inclusion of a lab experiment just for the purpose of exposing virtual private networks to the students. They could manually configure the networks themselves and learn more about setting up a VPN than could be explained to them either in a textbook or a lecture.

Because the lab was small and the number of students was large, the class was divided into five sections of eight students, and each section would meet at a specific time in the lab. Lectures for the entire class were also held, but in another, larger classroom. We next discuss the concepts presented in the classroom and then the experiments performed in the lab and show how these experiments complemented the class work.

\section{Classroom Concepts}

Classroom concepts that are based on sound theory change little over time, even where high technology is concerned. It is the implementation of these concepts that changes and this change can be considerable. To the extent that the technology we use in our laboratories supports the learning of these "ageless" concepts, then the better the pedagogical outcome. For example, using a layered model to allow computers to communicate (e.g., the OSI 7 layer model) in which the layers maintain independence, allows designers to change activities, functions and protocols at each layer without affecting other layers. This might be considered "ageless," because it is expected to vary only slightly in future modifications; however, the way in which the functions at each layer 
are implemented may vary considerably. Our teaching efforts should therefore focus more on the layered model and its functions and less on the mechanism by which protocols perform these functions.

Striking a balance between the theoretical presentations of the classroom and the technical goals of the lab has been shown to have certain advantages. It can accommodate different learning styles and it can help students combine practice with theory (Gutierrez \& Tawa, 2003). For business students there must be

Concepts introduced in the classroom fall into two broad categories - technical and business. The learning objectives for any MIS course taught in the business college must be to relate the technical concepts to the needs of the business. An organization cannot create a new information system for the fun of it; it must do so for some business reason. It is therefore necessary to relate the technical issues of the information system curriculum with the business needs and demonstrate how these needs are met using the technology. For example, we first introduce the concept of communications between computers by examining what it is and how we accomplish it. We then must answer the question of why a business needs to connect its computers together. The answer to the latter directly targets business issues such as efficiency, productivity and competitiveness. It is not enough however, to say that a new network will improve efficiency, increase productivity and enhance our competitiveness; we must also teach the student how to evaluate different technical alternatives and choose the solution with the best cost to benefit ratio. As students explore the technology that is available, they must be exposed to the advantages, the disadvantages, the costs and the potential benefits of each in order to accomplish this training objective. If they learn this process, they then can become skillful in applying it to future technological choices that they may face.

Given this basis, the technical areas that are commonly addressed in networking classes include the following:

1) Introduction to computer-to-computer communications,

2) Network architectures and topologies,

3) Communications protocols and standards including the OSI 7 layer model,

4) Hardware,

5) Software (network operating systems),

6) Network growth and management, and

7) Network security.

Business decisions that must be made include:

1) Acquisition of hardware and software to support the network,

2) Installation and implementation of the network,

3) Maintenance of the network,

4) Management of the resources and assistance for the users, and

5) Expansion and growth of the network.

There are several textbooks that provide excellent discussions of all of these issues including Dennis (2002), Fitzgerald and Dennis (2002), Goldman and Rawles (2000), Panko (2003),Stallings (2001), and Stamper and Case (2003). Some textbooks are more technically oriented than business students really need, and so care must be exercised when choosing the text. All but one of the aforementioned textbooks included the word "business" in the title. Although 
this does not guarantee that the textbook may be suitable for a particular class, I reviewed an equal number of texts without the word "business" in the title, and these texts seem to have a greater emphasis on the technical issues beyond what a student in the college of business might need. As a quick check on the focus of the textbook, look up the word "bandwidth" in the index and read the author's treatment of the concept. If it consists of 5 pages of explanation with a series of graphs of sine waves showing how they are added to odd harmonics to form a square wave, this textbook probably contains more of an engineering focus than the average business student should be exposed to. At the opposite extreme, if the author's definition of bandwidth is that it is equal to throughput, then this treatment might be a bit scant. A similar comparison can be made with the word, "Kerberos" and the concept of public key encryption. Lastly, when you look through the text as various technologies are introduced, are there reasons listed as to why an organization might choose one technology over another? For example, a common topic in many textbooks is redundant array of inexpensive disks (RAID) systems. RAID systems are categorized by level, so look to see if each level might be discussed not just in terms of its technical features, but its relative cost and why an organization might choose level 1 or level 5. You may not find a textbook that holds up to your scrutiny under all conditions, but these are good gauges to help you make the choice.

The next decision for the instructor is how to structure the lab experiments and to decide on which experiments offer the greatest learning opportunity for the business student. The choice of experiments needs to provide a balance between technical issues and the business issues that the technology is intended to address. Given a 16 week semester, the experiments need to cover the material adequately, introduce concepts that show the student how a technical solution meets the business needs and reinforces both technical and business concepts learned in the classroom.

\section{Laboratory Projects}

The focus of the lab projects was threefold: first, each project needed to reinforce those concepts learned in the classroom; second, each project was assigned to allow the student to do something that they had never actually performed themselves; and third, lab projects were progressive, that is, each subsequent project used the previous lab as a basis and continued from that point.

Concepts presented in the classroom were not simply technical in nature, but included the underlying business reasons for making decisions regarding acquisition and implementation of equipment and software configurations. Not only did the projects in the lab reinforce the classroom concepts, but the classroom discussion mapped lab activities directly into the business decision process. As an example, lab 3 required students to setup a member server and lab 4 promoted this server into a domain controller. Classroom discussion then included the reasons for choosing a member server or a domain controller and how this choice would affect a business.

With the exception of the first two lab projects, activities for the projects were chosen such that the students had no prior experience (or very little) in each topical area. Many students had set up web servers before, but very few had experience with the Apache web server and none had set up a web server that hosted more than one web site. The class was not a simple extension of previous work in systems analysis and design classes or database classes, but served to introduce the student to new areas where computer communications and connectivity are important. Most students had not worked with servers and server software before this class, and by doing so, it helped to introduce them to the need for increased power in a server, and to the reasons why a business can afford very little server down time. This in turn helped to emphasize concepts such as how multiple servers can improve reliability and the need for tight security.

Because the projects were "progressive," this allowed students to build upon previous activity through practice. For example, students learned how to share files in lab 1 and were asked in later labs to move files from one computer to another to practice these skills. This also had the effect 
of reducing the amount of detail contained in the lab instructions. The progressive nature of the projects also simulated building a network capable of "e-business" at the end of the semester. When finished, each student group had assembled a lab that consisted of a valid domain under the control of a domain controller. The server had the following capabilities: web home pages, ftp services, e-mail services, imaging, performance monitoring and control and secure external access over a public network. Secure wireless networking

A total of 13 projects were designed and used. They are listed in Table 1 along with a description of each. Also provided is a reference to concepts taught in the classroom to which each experiment was designed to reinforce.

Table 1: Lab Project Listing

\begin{tabular}{|c|c|c|c|}
\hline & Name & Description & Concepts reinforced \\
\hline 1 & $\begin{array}{l}\text { Peer-to-peer } \\
\text { networking }\end{array}$ & $\begin{array}{l}\text { Physically connect two computers and } \\
\text { share resources }\end{array}$ & $\begin{array}{l}\text { Resource sharing; general intro- } \\
\text { duction to computer communica- } \\
\text { tions }\end{array}$ \\
\hline 2 & $\begin{array}{l}\text { Network } \\
\text { physical } \\
\text { media }\end{array}$ & $\begin{array}{l}\text { A look at the hardware required to complete } \\
\text { the connections between computers includ- } \\
\text { ing cabling, network interface cards, } \\
\text { switches and routers }\end{array}$ & $\begin{array}{l}\text { Physical layer components, net- } \\
\text { work architecture and topologies }\end{array}$ \\
\hline 3 & $\begin{array}{l}\text { Server setup } \\
\text { part } 1\end{array}$ & $\begin{array}{l}\text { Loading server software and setting up user } \\
\text { accounts }\end{array}$ & $\begin{array}{l}\text { Client/server, rudimentary user } \\
\text { administration and security }\end{array}$ \\
\hline 4 & $\begin{array}{l}\text { Server setup } \\
\text { part } 2\end{array}$ & $\begin{array}{l}\text { Promoting the server to a domain controller, } \\
\text { setting up DHCP and DNS }\end{array}$ & $\begin{array}{l}\text { Node and network addressing; } \\
\text { converting computer names into } \\
\text { numerical addresses }\end{array}$ \\
\hline 5 & $\begin{array}{l}\text { E-mail Server } \\
\text { setup }\end{array}$ & $\begin{array}{l}\text { Set up an e-mail server and user accounts } \\
\text { to allow electronic communications to be } \\
\text { sent, stored and retrieved either on a local } \\
\text { account or using a web browser }\end{array}$ & $\begin{array}{l}\text { Internetworking communications; } \\
\text { network configuration administra- } \\
\text { tion }\end{array}$ \\
\hline 6 & $\begin{array}{l}\text { FTP Server } \\
\text { setup }\end{array}$ & $\begin{array}{l}\text { Setting up an FTP repository that would } \\
\text { allow users to upload and download files }\end{array}$ & $\begin{array}{l}\text { File transfer protocols and meth- } \\
\text { ods; security }\end{array}$ \\
\hline 7 & $\begin{array}{l}\text { Web Server } \\
\text { setup }\end{array}$ & $\begin{array}{l}\text { How to set up a web server that would host } \\
\text { multiple accounts }\end{array}$ & $\begin{array}{l}\text { Web server configuration; elec- } \\
\text { tronic commerce }\end{array}$ \\
\hline 8 & $\begin{array}{l}\text { User profiles } \\
\text { and wireless } \\
\text { networking }\end{array}$ & $\begin{array}{l}\text { Configuring the server to accommodate a } \\
\text { user regardless of where or how he or she } \\
\text { logs on to the domain }\end{array}$ & User privileges and access \\
\hline 9 & $\begin{array}{l}\text { Capturing } \\
\text { packets }\end{array}$ & The installation and use of a "packet sniffer" & $\begin{array}{l}\text { Performance measurement; moni- } \\
\text { toring of user actions; security }\end{array}$ \\
\hline 10 & Imaging & $\begin{array}{l}\text { Creating a model computer, loading this } \\
\text { image to a server and later broadcasting it } \\
\text { to the entire lab }\end{array}$ & Workstation configuration \\
\hline 11 & $\begin{array}{l}\text { Virtual private } \\
\text { networking } \\
\text { (VPN) }\end{array}$ & $\begin{array}{l}\text { Setting up a VPN to connect two sub- } \\
\text { networks across a public medium }\end{array}$ & $\begin{array}{l}\text { Security; performance and band- } \\
\text { width control; cost reduction meth- } \\
\text { ods }\end{array}$ \\
\hline 12 & $\begin{array}{l}\text { Technical } \\
\text { support }\end{array}$ & Responding to a trouble call & $\begin{array}{l}\text { Difficulties faced by tech support } \\
\text { personnel as they tackle a user } \\
\text { problem }\end{array}$ \\
\hline 13 & $\begin{array}{l}\text { Public key en- } \\
\text { cryption }\end{array}$ & How public key encryption works & Security \\
\hline
\end{tabular}

Students were required to report on their findings in a formal written report that was completed as a group. Assigning students to the groups was done so that the more experienced students could help the less experienced ones. This seemed to greatly benefit some students who had no previous exposure to networking concepts and applications. A slot-code reader was placed in the lab and students were required to swipe their student ID cards when they entered and when they left. By doing so, the students were entered into a database that recorded their time of entry and exit. The 
database then provided a report at the end of each week that documented each student's time spent in the lab with their group. By observing the interaction among the students in the first few labs and using the recorded attendance records in the database, the contribution from each student could be easily and accurately estimated. Students observed to have a stronger mastery of the lab material were encouraged to allow other students in their group to perform a larger proportion of the work. Spot checking this activity throughout the semester is a way that this policy can be enforced.

\section{Results}

Although difficult to quantify the amount of learning achieved by the students, the overall average for the class during the first semester was $78.3 \%$, and the entire class spanned about 10 points from this average on either side. Scores were taken from 10 weekly quizzes, 3 exams and twelve of the thirteen lab reports. Lab 13, the public key encryption lab, was not scored because it was completed as an exercise in class rather than a formal lab experiment. The number of graded items serves to highlight the amount of material that the students were exposed to and assessed on, and to show that their total score is reflective of the entire semester's work. The tightly grouped overall scoring and the weighting of the scores on the testing side (versus the lab reports) seem to indicate that the labs were beneficial in contributing toward the students' overall mastery of the course material. Over the course of six semesters, the class average has gradually climbed to $82 \%$ for exams and $92 \%$ for lab reports.

In situations where students needed to repeat actions in later labs that they had first been introduced to in earlier labs, the amount of material that the students had mastered became clear. It took them less time to accomplish simple configuration changes and/or to locate and solve problems that confronted them. As an example, an informal observation revealed that it took students between 30 and 45 minutes to promote a server to a domain controller in lab 4 and about half that amount of time when they were faced with doing it again for lab 8.

The most often heard comment from students as they left the lab was that they had never done this before. When queried further, they generally responded that they both appreciated this unique opportunity to learn and enjoyed getting their hands on the computers and performing the steps of the lab.

Two labs that seemed to draw the most attention and excitement from the students were lab 9, packet sniffing and lab 10, imaging. The packet sniffing lab required the students to map protocol headers and trailers into the captured packets to help them more clearly understand the protocols and the 7-layer model. Additionally, this lab allowed them to discover unencrypted passwords and to discover some standard sequences, such as the process of setting up a connection (in TCP) and tearing it down again. This lab provided students with startling visual evidence that security in computer networks requires major emphasis in businesses and that it cannot be taken for granted.

In the imaging lab, students prepared a model computer with all of the required software and configured it as a workstation attached to a domain. They prepared this image from instructions that specified a standard configuration for each computer within a fictitious organization. They then uploaded the image to the server and saved it as an image file. The size of this file averaged 2.8 gigabytes and included the operating system, word processing, spreadsheet and other applications required for a typical office setting. All lab computers were preset with the wake-on-LAN feature enabled. Students then were required to remotely load client software on each workstation from the server. All computers were then turned off and the image download was begun. Each computer instantly turned itself on and booted up first into Windows and then restarted in DOS using the client software previously mentioned. Once all computers were logged on to the session, the 
download began. This process was monitored by the students from both the server and the workstations and they were required to calculate the average data throughput using the figures displayed on the screens at the end of the process. The average was 80 Megabits per second (on a $100 \mathrm{Mbps}$ network) for multicast and $17 \mathrm{Mbps}$ for unicast. The students were then asked to explain why they were not achieving the full bandwidth capability of the network; a question which (initially) eluded many of them.

Finally, lab reports were much different than expected. Although some students simply put in the minimum amount of effort to document their actions and findings, a surprising number of students went further and explored the topics in greater depth. As an example, here are some excerpts from one group's report on lab 9, "Capturing packets" in which they used a program called "Ethereal" to monitor computer-to-computer communications:

\section{“Results}

This was probably one of the more interesting labs that we have done. Being able to see what information is passed through a network within a single program was somewhat amazing. We were surprised to find out that you could see the password for the FTP server when capturing the packets during that section of the lab. FTP definitely has some security issues.

\section{Conclusion}

This lab was very interesting. It made us much more aware of the security issues that are involved with any kind of technology sharing information. We learned that your information is not always safe when sending it over a network or the Internet. We didn't have any difficulties besides installing an FTP server on one of the workstations, but the installation went very smoothly."

Students were required to include the implications to business in their lab reports. The lab reports thus served three purposes. First, they documented the students' activities in the lab as a measure of their learning. Second, they helped the students learn how to communicate technical details to both technical and non-technical audiences. This was a major emphasis of the lab reports and grades for reports were adjusted downward for poor or unclear explanations and descriptions. Third, the report forced the students to go beyond the technical details and research the reasons why particular configurations of hardware and software might be better (or worse) for an organization.

\section{Summary and Conclusions}

The acquisition, installation, implementation and creation of experiments for this networking lab were started at the end of a spring semester and continued throughout the summer months. The lab was completed and ready to go for students at the beginning of the fall semester. In order to accomplish this, each lab was researched, written (with the help of a graduate student), tested and revised as necessary so that students could accomplish the assigned tasks within the time allotted. It was achieved at very little cost and the payoff for this investment could be seen in the smiles on the faces of the students as they exited the lab. As the example taken from an actual lab report shows, it appears that the students learned a lot and had a good time doing so. The College of Business does not train its graduates to become network engineers, it trains them to understand and deal with technical issues so that as managers in the future, they will be able to understand the technical issues that the engineers face. This then can help them make critical business decisions in this information age. This is an important contribution for our discipline because the Bureau of Labor Statistics projects that network systems and data communications analysts will be 
the second fastest growing occupational group through the year 2012, having an overall annual increase of whopping $57 \%$ and requiring a bachelor's degree

(http://www.bls.gov/emp/emptab3.htm ).

Educators who want to include networking in their IS curriculum need to consider adding a laboratory as part of the course of instruction. Teaching the course without a hands-on lab can be difficult for both the student and the instructor, but including a lab requires that decisions be made regarding the makeup of the hardware and software and more importantly, the content of the lab experiments so that they augment both technical and business concepts taught in the classroom. This paper has presented some of the obstacles to creating a networking lab and has discussed how to overcome them. It has also presented a short list of reasons and evidence why the lab can be successful and worth the hard work that it requires.

\section{References}

Alter, S. (2003). Sidestepping the IT artifact, scrapping the IS silo, and laying claim to "Systems in organizations." Communications of the Association for Information Systems, 12. Retrieved from http://cais.isworld.org

Dennis, A. (2002). Networking in the Internet age. New York: John Wiley \& Sons.

Fitzgerald, J. \& Dennis, A. (2002). Business data communications and networking (7th ed.). New York: John Wiley \& Sons.

Goldman, J. E. \& Rawles, P. T. (2000). Local area networks: A business-oriented approach (2nd ed.). New York: John Wiley \& Sons.

Gutierrez, J. \& Tawa, K (2003). Balancing theoretical and practical goals in the delivery of a universitylevel data communications program. Annals of Cases on Information Technology, 5, 290-301.

Hamza, M. K., Alhalabi, B., Hsu, S., Larrondo-Petrie, M. M., \& Marcovitz, D. M. (2003). Remote labs: The next high-tech step beyond simulation for distance education. Computers in the Schools, $19(3,4)$, 171-190.

Panko, R. (2003). Business data networks and telecommunications (4th ed.). Upper Saddle River: Prentice Hall.

Stallings, W. (2001). Business data communications (4th ed.). Upper Saddle River: Prentice Hall.

Stamper, D. A. \& Case, T. L. (2003). Business data communications (6th ed.). Upper Saddle River: Prentice Hall.

U.S. Department of Labor, Bureau of Labor Statistics, (2004). Monthly Labor Review Online, Feb. 2004. Retrieved from http://www.bls.gov/opub/mlr/2004/02/contents.htm

\section{Biography}

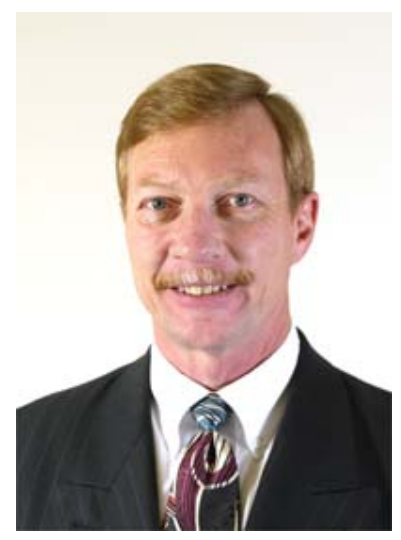

Michael A. Chilton is an assistant professor at Kansas State University where he teaches database and networking. His research interests include networking security, evaluation of IT personnel and IT pedagogical issues. He has published in the Database for Advances in Information Systems and others. 